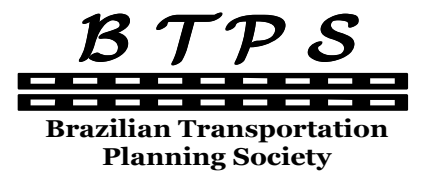

Planning Society
Journal of Transport Literature

Vol. 7, n. 2, pp. 146-170, Apr. 2013

Research Directory

\section{JTL|RELIT}

www.transport-literature.org ISSN 2238-1031

\title{
Análise do potencial de integração da bicicleta com o transporte coletivo em Belo Horizonte
}

[Analysis of the potential integration of cycling with public transport in Belo Horizonte]

\author{
Catarina Miranda Sampaio e Castro, Heloisa Maria Barbosa*, Leise Kelli de Oliveira \\ Universidade Federal de Minas Gerais (UFMG), Brazil
}

Submitted 17 May 2012; received in revised form 25 Jun 2012; accepted 11 Jul 2012

\begin{abstract}
Resumo
A bicicleta como um modo de transporte sustentável tem ganhado destaque por contribuir para a redução do número de veículos motorizados nas cidades. Para que isto ocorra, dentre os fatores que precisam ser fomentados, está a integração da bicicleta com o transporte público. Este artigo apresenta os resultados da análise da potencialidade da integração da bicicleta com o trem metropolitano, e a análise comparativa dos resultados em diferentes capitais brasileiras. A metodologia envolveu uma pesquisa de dados socioeconômicos e de preferência declarada para identificar os atributos relevantes para a ocorrência da integração, com usuários da Estação Vilarinho em Belo Horizonte. Os resultados apontam o perfil dos usuários dispostos a fazer a integração, e, a distância da origem até à estação e o fato de não possuir bicicleta como os motivos da falta de interesse pela integração. Os entrevistados declararam que segurança pública e infraestrutura cicloviária são fatores importantes para a integração. Além disso, não existe uma convergência do percentual de adesão à integração nas cidades analisadas, sendo necessários estudos locais para avaliar a viabilidade desta integração.
\end{abstract}

Palavras-Chave: ciclismo, integração de bicicleta, transporte público.

\begin{abstract}
Bicycle as a sustainable transportation mode has gained importance as it contributes to reduce the number of motorized vehicles in the cities. In order to this occur, among the factors that need to be encouraged is the integration of cycling with public transportation. This paper presents the results of the analysis of the potential of cycling integration with the metropolitan train and the comparative analysis of the results in different Brazilian capitals. The methodology involved a socioeconomic survey and stated preference to identify the relevant attributes to the occurrence of integration, among users at Vilarinho station in Belo Horizonte. Results indicated the users profile prone to the integration and, distance from origin to the station and the fact of not having a bicycle as reasons for the lack of interest in integration. Interviewees stated that public security and cycling infrastructure are important factors for integration. Moreover, there is not a convergence of the percentage of adherence for integration in the examined cities, and local studies are necessary to evaluate the integration feasibility.
\end{abstract}

Key words: cycling, bicycle integration, public transportation.

*Email: heloisa@etg.ufmg.br.

\section{Recommended Citation}

Castro, C. M. S., Barbosa, H. M. and Oliveira, L. K. (2013) Análise do potencial de integração da bicicleta com o transporte coletivo em Belo Horizonte. Journal of Transport Literature, vol. 7, n. 2, pp. 146-170.

- JTL/RELIT is a fully electronic, peer-reviewed, open access, international journal focused on emerging transport markets and published by BPTS - Brazilian Transport Planning Society. Website www.transport-literature.org. ISSN 2238-1031. 


\section{Introdução}

Nas últimas décadas, devido ao desenvolvimento econômico e social, as necessidades de mobilidade cresceram e alteraram-se significativamente, sobretudo, nos espaços urbanos. Como causas, pode-se citar a dispersão urbanística residencial e a descentralização das atividades e dos serviços resultantes do modelo de desenvolvimento urbano através da expansão permanente, de baixa densidade, da fronteira urbana, impulsionado pelo modelo de planejamento urbano e pelas políticas de financiamento e produção de habitação e infraestruturas de circulação e saneamento decorrentes do processo de urbanização acelerada ocorrido no país (Ministério das Cidades, 2006). Segundo Gomide e Morato (2011), a circulação nas áreas densamente habitadas tem enfrentado sérios obstáculos diante da ocupação desproporcional do transporte individual motorizado sobre o coletivo nos espaços públicos. Os impactos desses modelos aliados à baixa incidência de medidas efetivas voltadas à mobilidade reforçam o círculo vicioso do congestionamento e da expansão urbana: "com o aumento do tráfego, o transporte público torna-se mais lento e menos confiável, reduzindo sua demanda e sua receita. São necessários mais veículos para prestar o mesmo serviço e os custos aumentam. Os usuários cativos do transporte público são prejudicados e usuários potenciais são desestimulados. Aqueles que podem transferem-se para o transporte particular, aumentando o congestionamento e alimentando o círculo vicioso.” (ANTP, 1997). O aumento do rendimento das famílias é um dos fatores contribuintes para a transferência para o transporte particular. Segundo o TCU (2010), a despesa de consumo das famílias se elevou continuamente ao longo dos últimos sete anos e, em 2010, registrou variação positiva de 7\%, em função não apenas da manutenção da concessão de crédito às famílias, mas também devido ao crescimento em termos reais de $8,2 \%$ da massa salarial dos trabalhadores.

Diante do exposto, as cidades ficaram dependentes da utilização do transporte individual, face às deficiências do transporte coletivo, traduzindo-se no aumento de impactos negativos na sociedade, a nível econômico, social e ambiental.

Segundo o Ministério das Cidades (2007), as atividades de transporte e mobilidade, em todas as suas dimensões, constituem um setor que produz fortes impactos no meio ambiente, tanto diretamente, pela emissão de poluentes ou pelo efeito dos congestionamentos, quanto 
indiretamente, ao servir como fundamental elemento indutor do desenvolvimento econômico e urbano.

A bicicleta, como meio de transporte, tem sido incentivada em todo o mundo de forma a conscientizar as pessoas para as questões ambientais do planeta. É um veículo econômico, não poluente, flexível nos deslocamentos e um grande impulsionador para a saúde do utilizador. A inclusão da bicicleta como modo de transporte regular nos deslocamentos urbanos deve ser abordada considerando o conceito de Mobilidade Urbana Sustentável, e também por representar a redução do custo da mobilidade para as pessoas. Sua integração aos modos coletivos de transporte deve ser buscada principalmente junto aos sistemas de grande capacidade (Ministério das Cidades, 2007).

Nos últimos anos, os Órgãos Governamentais Brasileiros, responsáveis pelos setores de planejamento urbano e transporte, têm tido um papel importante na promoção da sustentabilidade da mobilidade urbana. Para isso, têm recorrido à bicicleta, promovendo-a como um meio de transporte sustentável, que contribui para a redução do número de veículos motorizados nas cidades, preservando assim o ambiente, a saúde da população e influenciando a economia das pessoas.

Pretende-se com a inclusão da bicicleta ultrapassar barreiras do ponto de vista social, isto é, olhar para este meio de transporte como um recurso necessário para a mobilidade urbana sustentável e como um meio democrático de oferta de transporte urbano a toda a população. Desta forma, incluem-se as pessoas socialmente excluídas e concedem-se os direitos de cidadania a um maior número de habitantes, deixando para trás a ideia de um meio apenas utilizado em atividades de lazer. No Brasil, assim como em muitos outros países, pelo fato do automóvel ser um símbolo de status e prosperidade, a utilização da bicicleta em viagens utilitárias não é considerada uma opção adequada para alguns grupos sociais. Embora muitos possuam bicicletas, elas são utilizadas quase que exclusivamente para recreação (Pezzuto e Sanches, 2004). Segundo o Ministério das Cidades (2007), a bicicleta é o veículo individual mais utilizado nos pequenos e médios centros urbanos. A situação muda nas grandes cidades, com a expressiva oferta de transporte coletivo associado a um tráfego intenso, onde as viagens de bicicleta se encontram presentes nas áreas periféricas, cujas condições se assemelham às encontradas nas cidades pequenas e médias. 
No território brasileiro, segundo Vieira et al (2010) a participação do modo cicloviário ainda é pouco significativa, correspondendo a $3 \%$ do total de viagens (ANTP, 2008). Isso se deve em parte à pequena importância dada ao potencial dos veículos de tração humana, já que a maioria das cidades não possui infraestrutura adequada para a circulação segura e confortável do seu usuário. Segundo o Ministério das Cidades (2007), apesar da existência de cerca de 60 milhões de bicicletas no Brasil e da sexta maior frota de bicicletas do mundo, o país possui apenas 2.500 quilômetros de infraestrutura exclusiva à circulação de bicicletas.

Nesse contexto, este artigo tem como finalidade identificar os fatores que influenciam o uso da bicicleta e analisar como fomentar uma melhor qualidade de vida no meio urbano, tendo como principal destaque a mobilidade sustentável vinculada à integração da bicicleta ao meio de transporte público. O artigo apresenta os resultados da análise da potencialidade da integração da bicicleta com o trem metropolitano, e a análise comparativa dos resultados encontrados na literatura sobre o tema em diferentes capitais brasileiras. A metodologia adotada neste trabalho envolveu uma pesquisa de dados socioeconômicos e de preferência declarada para identificar os atributos relevantes para a ocorrência da integração, realizadas com uma amostra de usuários da Estação Vilarinho em Belo Horizonte, Minas Gerais. A análise dos dados indicou o perfil dos usuários dispostos a fazer a integração da bicicleta com o transporte público, e, a distância da origem até à estação e o fato do usuário não possuir bicicleta como os motivos principais da falta de interesse pela integração. Os entrevistados declararam que "segurança pública eficiente" e a "existência de infraestrutura cicloviária" são fatores importantes para o interesse pela integração.

Este artigo está assim subdividido: na primeira seção são apresentados estudos e experiências sobre o uso da bicicleta como meio de transporte e os fatores que afetam o seu uso na integração com o transporte público. Na seção 2, objetivamente é feita uma análise do potencial da integração da bicicleta com o transporte coletivo na Estação Vilarinho em Belo Horizonte. Para tanto foram realizadas pesquisas de campo com aplicação da técnica de preferência declarada e de questionário socioeconômico, descritas nos itens 2.2 e 2.3. A análise desses dados permitiu traçar o perfil socioeconômico dos potenciais usuários de bicicletas, bem como investigar os atributos importantes para a integração da bicicleta com o transporte coletivo nomeadamente ônibus/metrô. Por fim, são apresentadas as principais conclusões a respeito do potencial da bicicleta para integração com o transporte público. 


\section{A bicicleta como meio de transporte}

Pezzuto e Sanches (2004) conduziram uma pesquisa para identificar os fatores que influenciam na escolha da bicicleta como modo de transporte com adolescentes entre 14 e 17 anos, divididos em três grupos: os ciclistas (que utilizam a bicicleta para viagens utilitárias), os ciclistas casuais (que utilizam a bicicleta somente para lazer e exercício) e os não usuários (não utilizam a bicicleta por nenhum motivo). A técnica estatística de análise fatorial foi o instrumento utilizado para a identificação dos fatores. Para o grupo dos ciclistas foram identificados dois fatores que interferem no uso da bicicleta: um relacionado ao conforto (de maior peso) e um relacionado à segurança (com peso menor). No que se referem à questão do conforto, os aspectos apontados são inerentes à própria bicicleta. Quanto à segurança, os aspectos estão relacionados à possibilidade de conflito com os veículos motorizados e à vulnerabilidade para assaltos. Os ciclistas casuais têm uma percepção subjacente da bicicleta como um modo de transporte desconfortável, inseguro, inferior aos veículos motorizados nos aspectos de velocidade e conforto, e que não pode ser utilizado em qualquer ocasião. De um modo geral, através deste estudo, pode-se concluir que os fatores, que mais influenciam o uso da bicicleta como modo de transporte, estão relacionados aos aspectos de conforto e segurança, às vantagens oferecidas pelos modos motorizados e a valores e preferências pessoais.

Pesquisa realizada em Porto Alegre, pela Empresa de Trens Urbanos de Porto Alegre Trensurb, no primeiro semestre de 2005, entrevistou 627 usuários do trem, nas cinco estações de maior movimento, de um total de 17 estações em toda a linha. Desses, 25,7\% declararam serem usuários da bicicleta e 14,3\% afirmaram fazer uso da integração da bicicleta com o trem, como forma de economia (Braga e Miranda, 2006). Conforme pesquisa de Ribeiro e Freitas (2005, apud Braga e Miranda, 2006), na cidade de Salvador, 60\% de 775 usuários de ônibus e trem, declararam que usariam a bicicleta se houvesse integração com o transporte coletivo, com instalação de estacionamentos. Nessa pesquisa, feita em quatro estações de trem, apenas $2 \%$ chegaram de bicicleta ao local, devido à deficiência de estacionamento, apesar de que $35 \%$ dos entrevistados faziam uso regular da bicicleta como modo de transporte e 53\% deles tinham ao menos uma bicicleta no domicílio. 
Providelo e Sanches (2006) propuseram um método para a definição de rotas cicláveis em áreas urbanas. A metodologia definida foi aplicada através de um estudo de caso em dois pólos geradores de viagens utilitárias por bicicleta na cidade de São Carlos, SP, Brasil. Os dados necessários para o estudo foram obtidos através da realização de 106 entrevistas, que incluíram um questionário para levantamento das características dos entrevistados e das viagens realizadas, e uma pesquisa de preferência declarada com três atributos: condições do pavimento, velocidade dos veículos e tempo de viagem. Os ciclistas também identificaram, na pesquisa, quais os pontos mais problemáticos do seu trajeto para andar de bicicleta. Dentre os resultados alcançados, destacaram-se os problemas relacionados a conflitos viários, como o tráfego de bicicletas em rotatórias e cruzamentos. Os dados obtidos na pesquisa de preferência declarada permitiram calibrar modelos do tipo Logit, Multinomial Explodido para estimar a importância relativa de cada atributo escolhido (velocidade dos veículos motorizados, tempo de viagem e condições do pavimento) para os entrevistados. Para a calibração do modelo foi utilizada a ferramenta Solver do programa Excel. A qualidade do modelo ajustado foi avaliada através dos parâmetros estatísticos: $\chi 2$ (qui-quadrado) e $\rho 2$. Os resultados indicaram que o atributo "pavimento" (qualidade do pavimento) teve o coeficiente de maior valor, sendo, portanto o mais importante para os entrevistados, em detrimento da velocidade dos veículos motorizados e do tempo de viagem que apresentaram coeficientes de magnitudes semelhantes.

A experiência holandesa de integração da bicicleta com o transporte coletivo apresenta lições para outros países, na visão de Martens (2007). Primeiro, a falta de atenção à bicicleta como modo alimentador para as viagens para o transporte público sugere que medidas para promover a integração da bicicleta com o transporte público, denominada bike-and-ride, são dificilmente prováveis de serem implementadas se não houver uma política explícita para integração. Segundo, a experiência holandesa mostra que o uso da bicicleta em viagens de acesso pode ser promovido simplesmente pela implantação de instalações suficientes e atrativas de estacionamento para bicicletas. Terceiro, as possibilidades de promover o uso da bicicleta para viagens de saída (egressa) em outros países e cidades são limitadas. O nível mais baixo de uso de bicicletas e a infraestrutura menos desenvolvida irão reduzir substancialmente o número de pessoas que poderiam considerar o uso da bicicleta como modo egresso de transporte. Ainda segundo Martens (2007), dada a experiência holandesa, a única medida que tem alguma chance de sucesso em outras cidades ou países é a bicicleta de 
aluguel. Cidades com uma infraestrutura cicloviária bem desenvolvida, como Munique, Cambridge, Copenhague, poderiam introduzir a bicicleta de aluguel em estações estratégicas de destino que não possuem uma malha densa de transporte público para viagens egressas, tais como estações de trem fora de áreas centrais com uso do solo como universidades, escritórios, centros de convenções localizados além de uma distância caminhável (3 a 4 km).

Uma pesquisa de atitude conduzida por Providelo e Sanches (2010) nas cidades de Rio Claro e São Carlos, no estado de São Paulo, investigou alguns fatores que influenciam na escolha da bicicleta como modo de transporte. O método escolhido para medir a percepção dos indivíduos foi a aplicação de questionários desenvolvidos com base na escala Likert. Os resultados da pesquisa de atitude possibilitaram o desenvolvimento de uma escala de aceitabilidade ao uso da bicicleta, que indica quão favorável os indivíduos são em relação ao ciclismo. Além disso, a análise da pesquisa de atitude indica que os fatores a respeito dos quais houve maior concordância positiva entre os entrevistados são os que demonstram o ciclismo como um transporte barato e bom para a saúde. Verificou-se também que existe diferença significativa com relação à aceitabilidade ao ciclismo entre os grupos separados por características: gênero (homens são mais favoráveis), idade (indivíduos mais velhos são mais favoráveis), tipo de ciclista (ciclistas que se consideram muito experientes são mais favoráveis e não ciclistas menos favoráveis), e frequência de uso da bicicleta (indivíduos que utilizam a bicicleta mais frequentemente são mais favoráveis).

Silveira, Balassiano e Maia (2011) estudaram o potencial de estações da Linha Centro do metrô de Recife - PE para integração com a bicicleta. A pesquisa teve abordagem social, de natureza qualitativa e foi formatada por meio de estudo de caso. O trabalho consistiu de duas etapas: uma de aplicação de questionários na plataforma de embarque de três estações do metrô selecionadas para a pesquisa; e outra de análise dos resultados do questionário, no qual foi aplicado o teste estatístico do Qui-quadrado. O questionário utilizado foi semiestruturado com questões objetivas e abertas, e teve perguntas sobre os aspectos socioeconômicos e as características dos deslocamentos, objetivando determinar o perfil dos potenciais usuários à integração bicicleta - metrô. $\mathrm{O}$ perfil dos usuários levantado nessa pesquisa indica que o gênero, a faixa etária e a ocupação das pessoas entrevistadas não influenciam no intuito de fazerem integração. Já com relação ao grau de instrução e a renda, notou-se que as pessoas de menor renda e de menor grau de instrução são mais propensas a fazerem integração da bicicleta com o metrô. Segundo os autores, no Recife, faltam políticas sustentáveis de 
incentivo ao uso da bicicleta como modo de transporte para todas as classes, programas educacionais para tráfego compartilhado entre ciclistas e motoristas e implantação de uma infraestrutura cicloviária que garanta a segurança do ciclista e uma rede integrada aos transportes públicos. Além disso, falta segurança pública para estimular o uso da bicicleta, bem como a integração bicicleta com o metrô. Na pesquisa de campo, o maior empecilho para o interesse na integração bicicleta com o metrô nas três estações selecionadas foi justamente a falta de segurança pública.

Monteiro (2011) apresentou o desenvolvimento de um procedimento para analisar os espaços urbanos no entorno de três estações de transporte de massa - Ipanema, Colégio e Pavuna na cidade do Rio de Janeiro - com a finalidade de auxiliar os tomadores de decisão na caracterização e localização de regiões que necessitem da aplicação de técnicas e políticas que priorizem o transporte de massa, pedestres, ciclistas e pessoas com dificuldade de deslocamento. A pesquisa de campo objetivou identificar o perfil do usuário do transporte de massa e principalmente, aqueles que chegam a pé e de bicicleta na estação do metrô. A pesquisa também serviu para conhecer a opinião dos usuários quanto à qualidade dos elementos que compõem os espaços percorridos até a estação e assim pôde-se observar a demanda potencial para a ampliação da integração do pedestre e ciclista com o sistema de metrô. Os resultados gerais da pesquisa indicaram a distância como o fator mais problemático em relação aos problemas encontrados na viagem de bicicleta, porém em duas circunstâncias, a proximidade entre a origem e destino, como o caso da estação de Ipanema ou pelo grande afastamento entre a origem e destino, como no caso da Estação da Pavuna, foram relatados como grandes empecilhos para a integração. A metodologia da pesquisa constou da seleção e cálculo de indicadores relacionados com a qualidade dos espaços urbanos, a fim de se obter variáveis locais e globais que demonstrem o quanto uma área urbana pode se tornar atrativa para as viagens a pé ou por bicicleta. A pesquisa também indicou que existe uma grande necessidade de adequação das calçadas e ciclovias nos bairros estudados (Ipanema e Pavuna na cidade do Rio de Janeiro) para a obtenção de um nível melhor de satisfação dos usuários, sendo necessárias fiscalizações rigorosas com relação ao uso e ocupação desses espaços e algumas intervenções inclusive no trânsito de veículos que por ali circulam. 


\section{Integração da bicicleta na Estação Vilarinho}

Em Belo Horizonte, atualmente o sistema sobre trilhos tem um papel bastante significativo face aos deslocamentos urbanos. De acordo com dados fornecidos pela Companhia Brasileira de Trens Urbanos - CBTU (2010) são transportados, em média, 148 mil passageiros por dia útil. Embora o trem metropolitano tenha um papel relevante no transporte coletivo de Belo Horizonte, ainda se encontra longe de responder a todos os problemas de transporte visto que sua rede ainda é pouco desenvolvida. O sistema opera com apenas uma linha com extensão de 28,2 km que engloba 19 estações e atende apenas dois municípios, Belo Horizonte e Contagem, e é constituído pelo trecho Eldorado/Vilarinho, com 19 estações e cinco terminais integrados.

A estação Vilarinho possui um setor de ônibus para linhas metropolitanas (setor Norte) e um setor para linhas municipais (setor Sul) adjacentes aos trilhos do Trem Metropolitano. No setor sul já opera um sistema alimentador com três linhas. É a maior estação intermodal (metrô/ônibus) do sistema de transporte coletivo da Região Metropolitana de Belo Horizonte - RMBH, localizada na Avenida Vilarinho, próxima ao entroncamento com a Av. Cristiano Machado e a MG-010, e de fundamental importância para os mais de um milhão de habitantes dos bairros da região Norte da capital e de seis outros municípios. Instalada em um terreno de $80 \mathrm{mil} \mathrm{m}^{2}$, no pavimento térreo abriga um centro comercial. A estação foi projetada para atender a uma demanda diária de cerca de 120 mil usuários e tem capacidade de circulação para uma frota de aproximadamente 400 ônibus nos horários de pico.

No sistema de transporte público existem atualmente três estações de integração ônibus/trem, a saber, Eldorado, Vilarinho e São Gabriel que constituem as estações mais movimentadas do sistema. Em todas elas existem paraciclos para estacionar bicicletas, mas efetivamente não se sabe se a integração da bicicleta com o trem é de fato executada, razão do desenvolvimento do estudo em questão.

Os itens seguintes descrevem os métodos adotados para a obtenção de dados junto aos usuários da estação Vilarinho, no intuito de conhecer o potencial que a bicicleta apresenta para realizar a integração com o transporte público, seja por ônibus ou trem metropolitano, nas viagens de acesso à estação, isto é, casa-estação e nas viagens egressas, estação-casa, fazendo uso de estacionamento para bicicletas na estação. 


\subsection{Coleta de dados}

Foi realizada uma pesquisa de campo na Estação Vilarinho nos dias 20 de Maio e 3 de Junho de 2011, com uma amostra de 170 pessoas entrevistadas. Foram efetuadas entrevistas no âmbito socioeconômico, com a finalidade de delinear o perfil dos usuários da estação e conduzida uma pesquisa de preferência declarada para avaliar a intenção da integração da bicicleta com os transportes coletivos, nomeadamente o trem metropolitano.

Inicialmente estipulou-se realizar no primeiro dia de pesquisa 100 entrevistas para ter um panorama das respostas dadas pelos usuários (amostra piloto), para posteriormente ser realizado o cálculo da amostra necessária para o estudo. Destes 100 entrevistados, obteve-se que 98 usuários nunca tinham usado a bicicleta para chegar à estação e apenas duas pessoas já tinham usado. Aplicando a fórmula para cálculo do tamanho da amostra para variáveis discretas com proporcionalidade, com grau de confiança de $95 \%$ e erro amostral de 5\%, obteve-se 30 elementos na amostra. Concluiu-se desta forma que a amostra de 100 entrevistas seria plenamente aceitável para o estudo. Mesmo assim foi realizado mais um dia de pesquisa com a coleta de 70 entrevistas, perfazendo assim um total de 170 entrevistas.

Para traçar o perfil dos potenciais usuários foi elaborado um questionário que envolveu questões relativas ao campo socioeconômico, tais como, gênero, idade, renda, ocupação e escolaridade; relativas ao padrão de viagem: motivo da viagem, meio de transporte utilizado e tempo de viagem até à estação; e questões específicas sobre o uso de bicicleta: sabe andar de bicicleta, obstáculos para o uso da bicicleta; motivos para não usá-la; local onde estaciona/guarda a bicicleta.

$\mathrm{Na}$ pesquisa de preferência declarada, foi solicitado aos entrevistados ordenar situações hipotéticas de integração da bicicleta com o metrô. O detalhamento da pesquisa será abordado no item 2.3.

\subsection{Perfil dos potenciais usuários para integração da bicicleta com transporte coletivo}

Das 170 entrevistas realizadas, $65 \%$ foram com pessoas do gênero feminino e $35 \%$ do masculino, amostra compatível com a população da Região, composta de 57\% de mulheres e $43 \%$ de homens, segundo o último censo do IBGE (IBGE, 2010). 
Em seguida avaliou-se o número de pessoas que sabiam andar de bicicleta, uma vez que se trata de uma característica importante para a integração da bicicleta com o transporte coletivo. Dos 159 entrevistados que sabiam andar de bicicleta, 65\% eram do sexo feminino e $35 \%$ do sexo masculino, verificando-se a mesma proporção de gênero em relação ao total dos entrevistados. A idade variou entre 10 e 70 anos, mas a faixa etária mais destacada em termos de respostas foi de 21 a 30 anos (Figura 1).

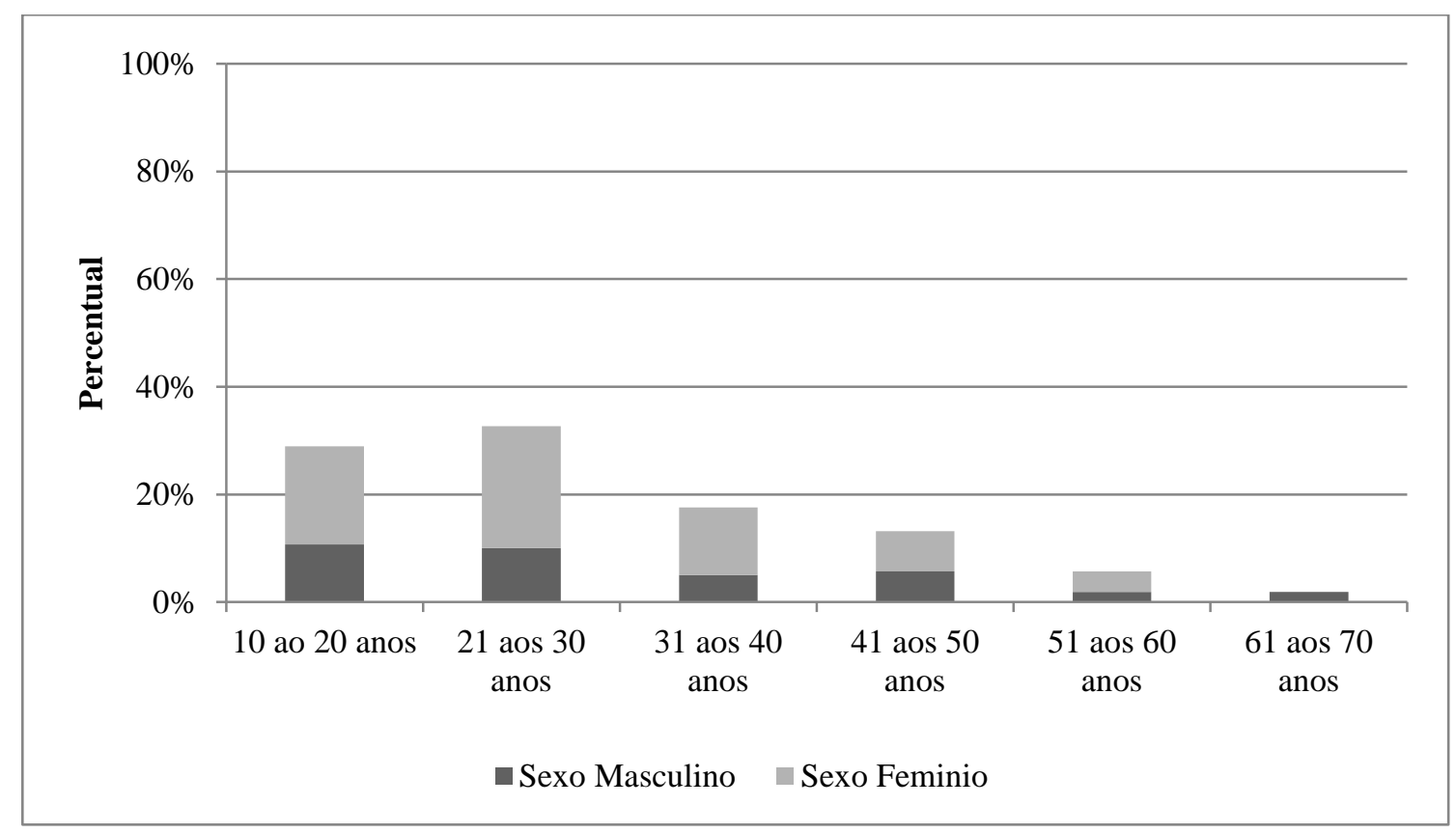

Figura 1 - Distribuição por faixa etária, do gênero dos entrevistados que sabem andar de bicicleta ${ }^{1}$

Na questão sobre a integração da bicicleta foi necessário fazer uma filtragem de informação para distinguir quais seriam os potenciais usuários de integração da bicicleta com transporte público daqueles que não estariam dispostos de forma alguma a utilizar a bicicleta como meio de transporte. Foram considerados como potenciais usuários da integração da bicicleta com o transporte coletivo todos aqueles que mencionaram que não usariam a bicicleta para o deslocamento até à estação por motivos relativos à falta de infraestrutura cicloviária, detalhados a seguir:

\footnotetext{
${ }^{1}$ Fonte: elaboração própria.
} 
- Condições precárias da via (poças, buracos, etc.);

- Insegurança pública (assaltos);

- Topografia acidentada (ladeiras);

- Falta de iluminação;

- Trânsito perigoso;

- Falta ciclovia;

- Falta de estacionamento adequado;

- Falta de banheiro ou vestiário na estação.

Os demais motivos, não associados à falta de infraestrutura, considerados como impeditivos para o uso da bicicleta foram: não possuir bicicleta, condições físicas desfavoráveis (idade, deficiência motora, etc.) e distância.

As pessoas que responderam que já teriam utilizado a bicicleta para o deslocamento até à estação também foram incluídas, perfazendo um total de 38 entrevistados potenciais de integração, $22 \%$ em relação ao total dos entrevistados. Dos potenciais usuários da bicicleta como modo de integração $95 \%$ eram do sexo feminino e 5\% do sexo masculino (Figura 2). O resultado encontrado nesta pesquisa referente à integração da bicicleta (22\% favoráveis) é muito diferente dos resultados obtidos para Salvador e Recife. Para Salvador, Ribeiro e Freitas (2005, apud Braga e Miranda, 2006) relataram que 60\% dos entrevistados usariam a bicicleta se houvesse integração com o transporte público com instalação de paraciclos. $\mathrm{O}$ estudo de Silveira (2010) para a cidade de Recife indicou que $86 \%$ do total de entrevistados tem interesse pela integração bicicleta-metrô, com homogeneidade entre homens e mulheres (respectivamente, 44\% e 42\%). No Rio de Janeiro, segundo Monteiro (2011), 12\% dos entrevistados usam a bicicleta para locomoção até as três estações de metrô consideradas no estudo (Ipanema, Pavuna, Colégio). Esses resultados indicam a inexistência de uma uniformidade no uso e na disposição para a integração da bicicleta com o transporte coletivo e, a necessidade de pesquisas locais para definir a demanda pelo serviço.

Em Belo Horizonte, dentre os motivos relatados para a falta de disposição para o uso da bicicleta com integração ao transporte coletivo, pode-se destacar: 
- Clima;

- Não sabe andar de bicicleta;

- Não possui bicicleta;

- Distância;

- Condições físicas (idade, deficiência motora, etc.);

- Outros motivos (sedentarismo, rapidez do ônibus face à bicicleta e residência perto da estação).

Do total de entrevistados, 132 declararam não fazer a integração da bicicleta com o metro, correspondendo a $78 \%$ dos entrevistados, em que $67 \%$ foram respondidos pelo gênero feminino e $33 \%$ pelo gênero masculino (Figura 2).

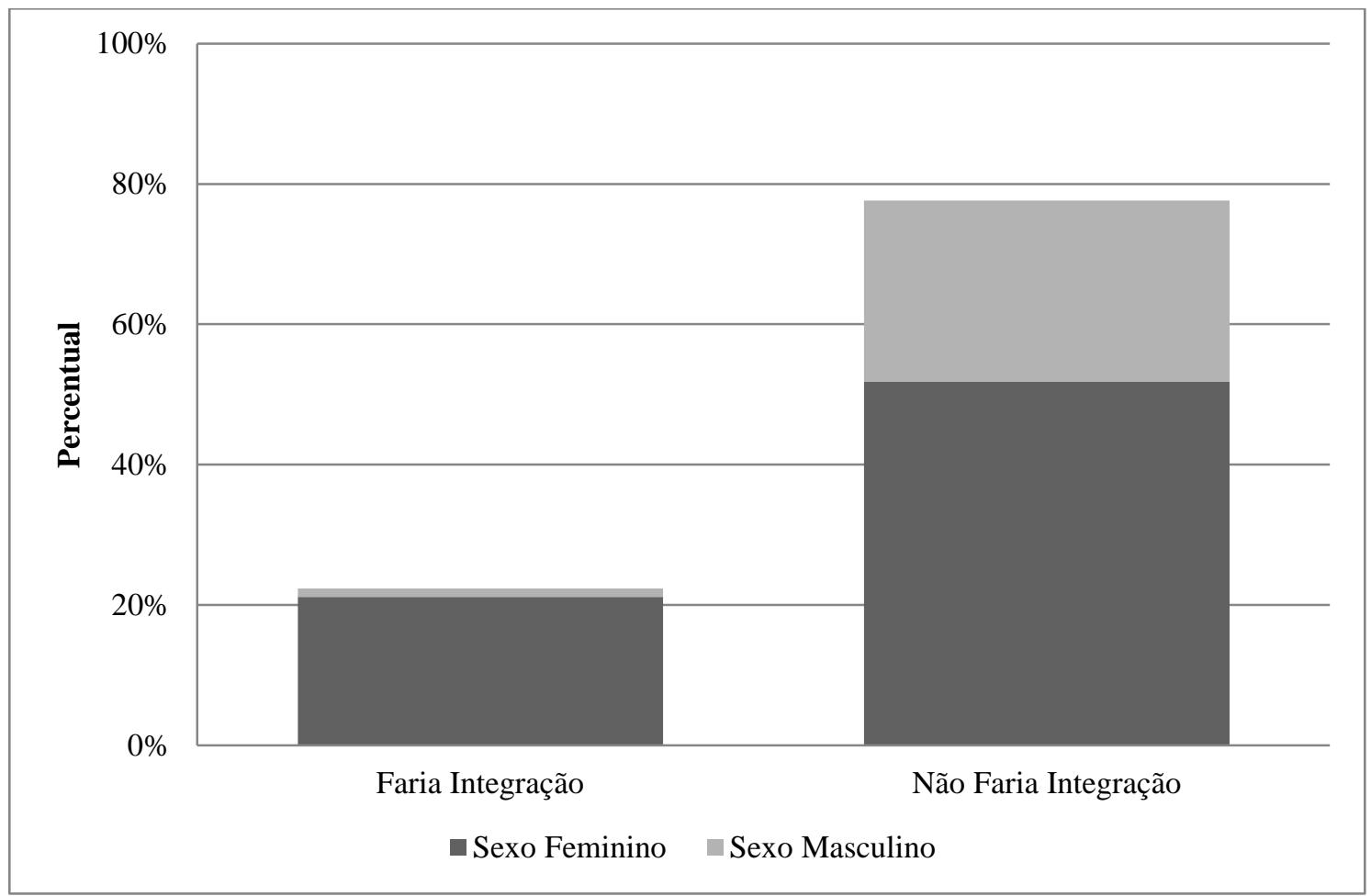

Figura 2 - Distribuição por gênero dos entrevistados da opção por integração da bicicleta ao transporte coletivo ${ }^{2}$

Relativamente ao meio de transporte utilizado pela população entrevistada para acessar a estação, destaca-se o ônibus com grande relevância, representando 63\% dos potenciais usuários de integração e $71 \%$ dos não potenciais ao sistema integrado (Figura 3).

\footnotetext{
${ }^{2}$ Fonte: elaboração própria.
} 


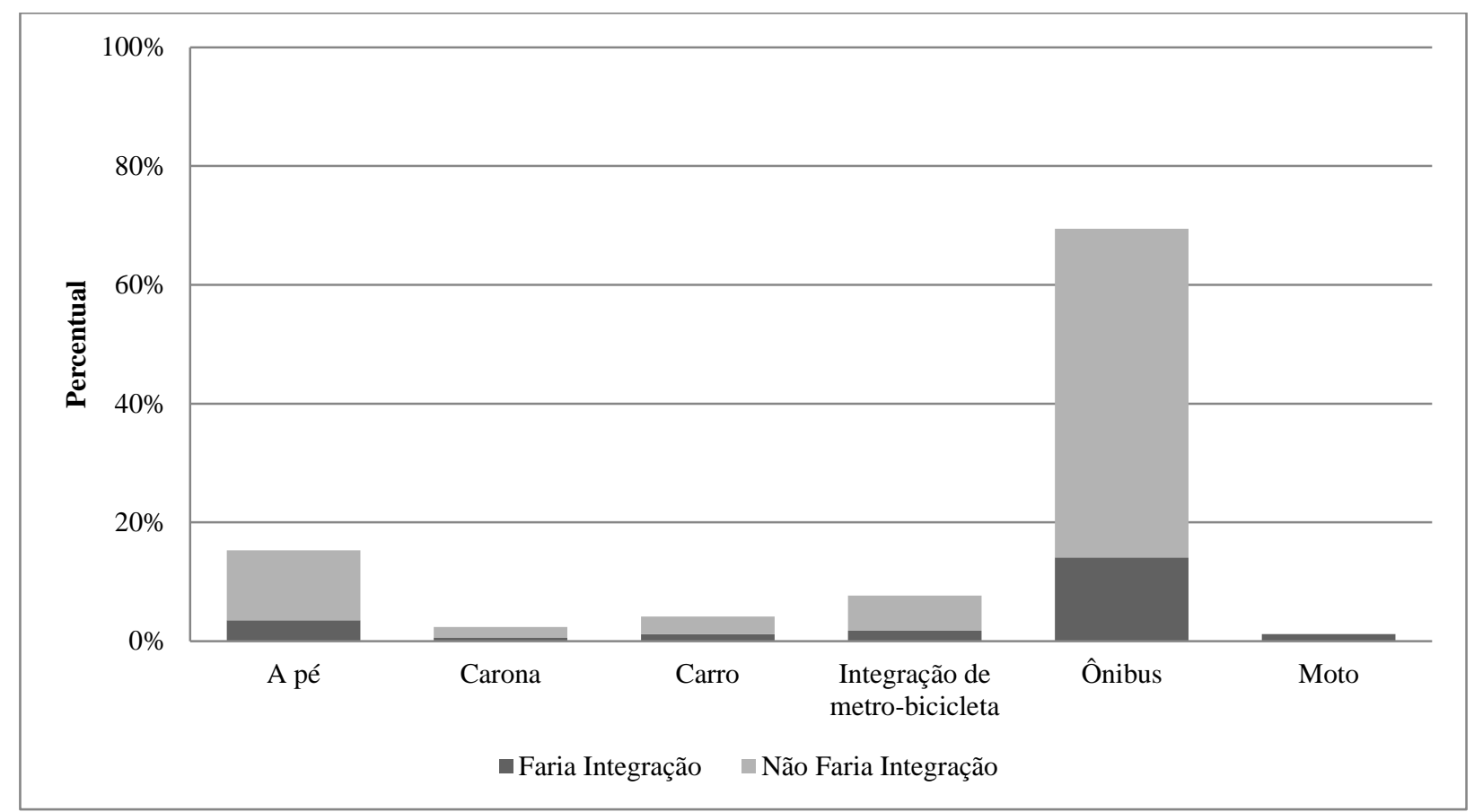

Figura 3 - Distribuição por meio de transporte utilizado,

\section{da opção de fazer ou não integração ${ }^{3}$}

No que diz respeito ao motivo de viagem, tanto para os potenciais usuários como para usuários não potenciais do sistema de integração, a opção Trabalho/Negócio destaca-se com um percentual de $58 \%$ e de $70 \%$, respectivamente (Figura 4 ).

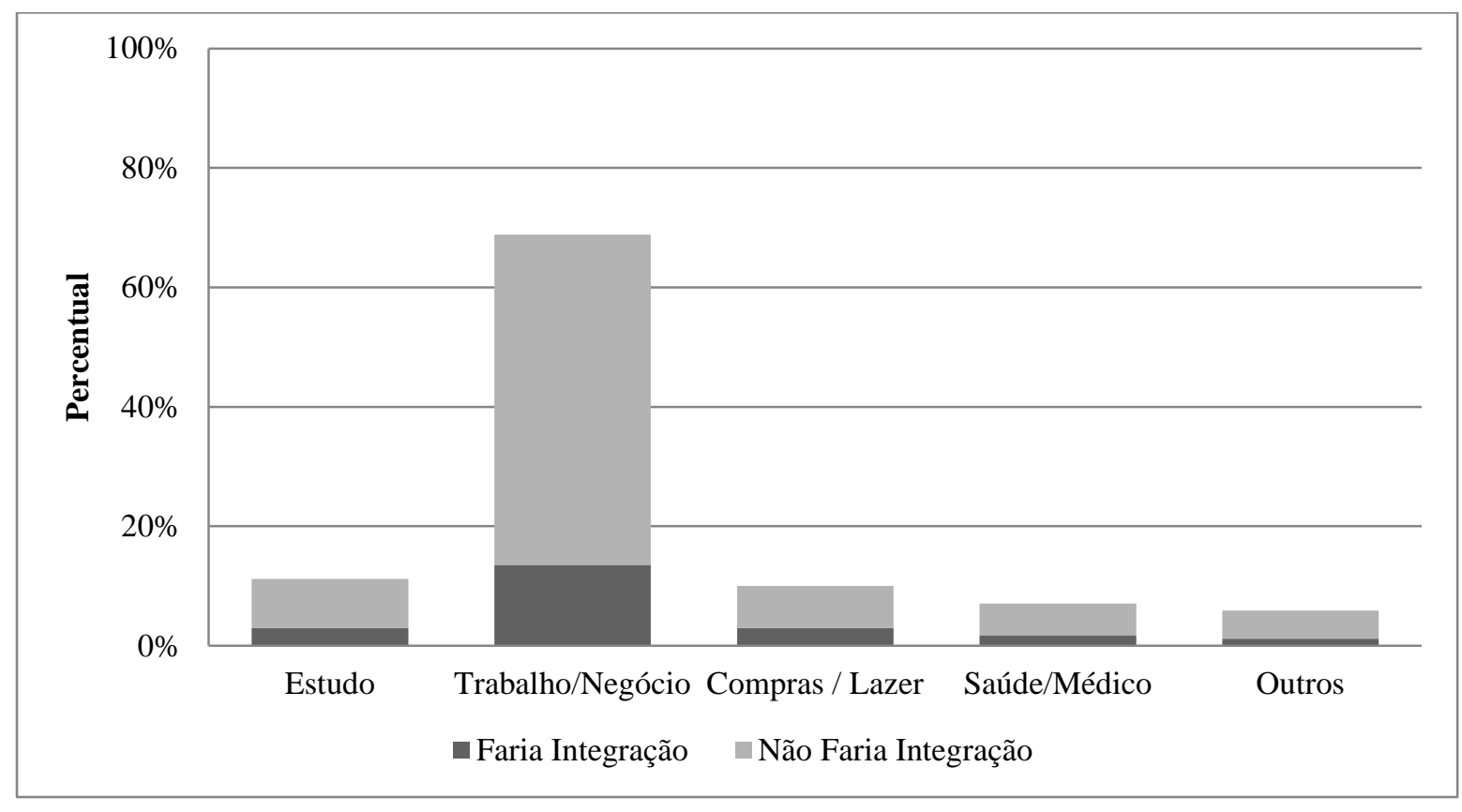

Figura 4 - Distribuição por motivo de viagem, da opção de fazer ou não integração ${ }^{4}$

\footnotetext{
${ }^{3}$ Fonte: elaboração própria.
} 
Quando se questiona sobre o tempo de viagem até a estação verifica-se uma grande variação nas respostas. Em relação aos entrevistados que não estão dispostos a usar a bicicleta como integração, os intervalos de tempo que mais se destacam são de 10 a 20 min e de 20 a 30 min, com $29 \%$ e $27 \%$, respectivamente, do total de 132 respostas. Dentre os usuários potenciais de integração destaca-se a resposta de 10 a 20 min com 37\% do total de 38 entrevistas (Figura 5).

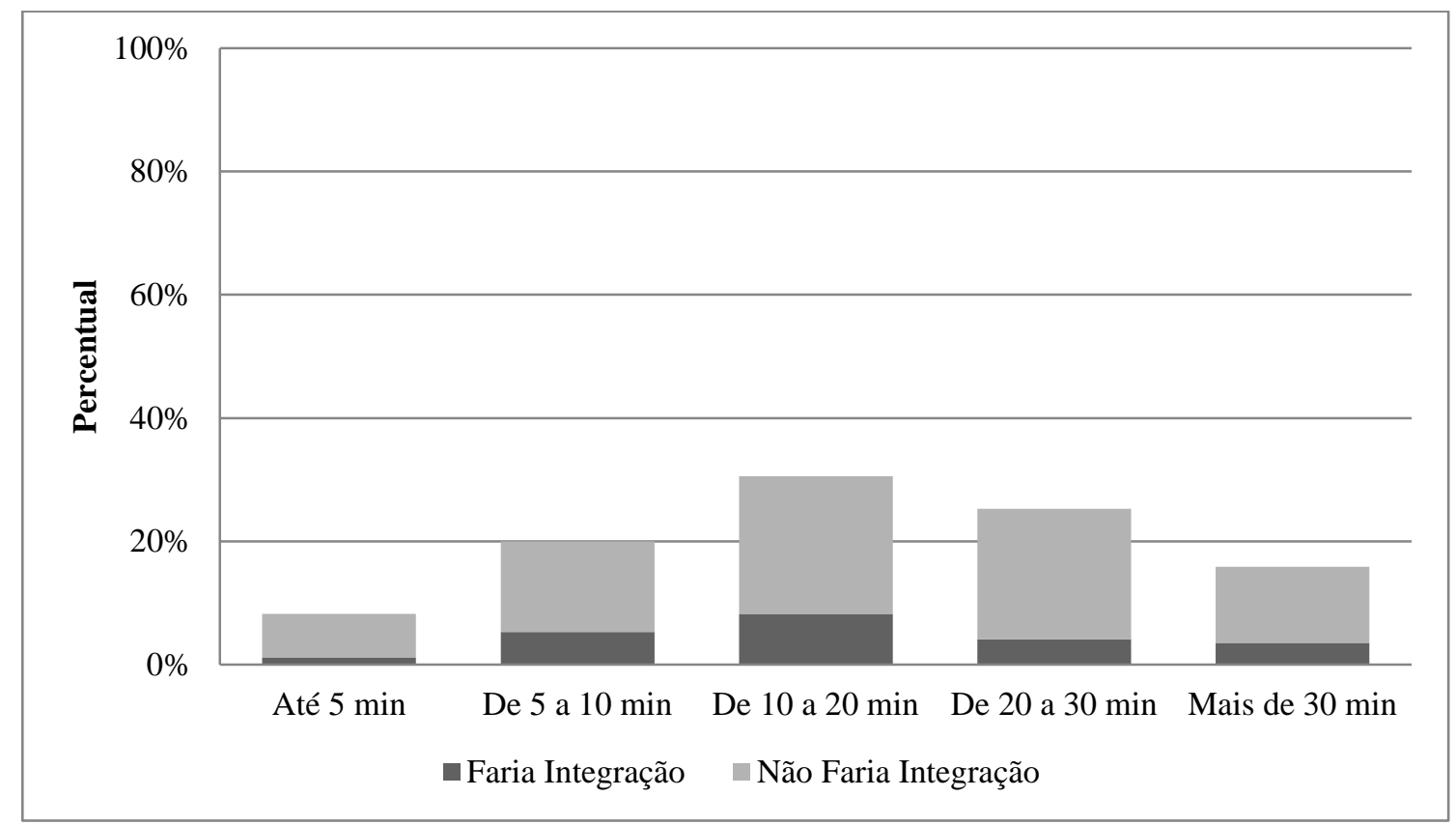

Figura 5 - Distribuição por tempo de viagem, da opção de fazer ou não integração 5

Na questão relativa à renda dos entrevistados, 34\% do total de indivíduos potenciais face à integração possui renda no intervalo de $\mathrm{R} \$ 545,00$ até $\mathrm{R} \$ 1.090,00$ (de 1 a 2 salários mínimos) (Figura 6). Considerando também a classe seguinte, de $\mathrm{R} \$ 1.090,00$ a $\mathrm{R} \$ 2.180,00$ totalizaria a maioria dos usuários dispostos a realizar a integração. Silveira (2010) notou que as pessoas de menor renda e de menor grau de instrução são mais propensas a fazerem integração bicicletametrô, no caso de Recife. Para os usuários da estação Vilarinho, é grande a parcela de usuários de baixa renda que não fariam a integração.

\footnotetext{
${ }^{4}$ Fonte: elaboração própria.

${ }^{5}$ Idem.
} 


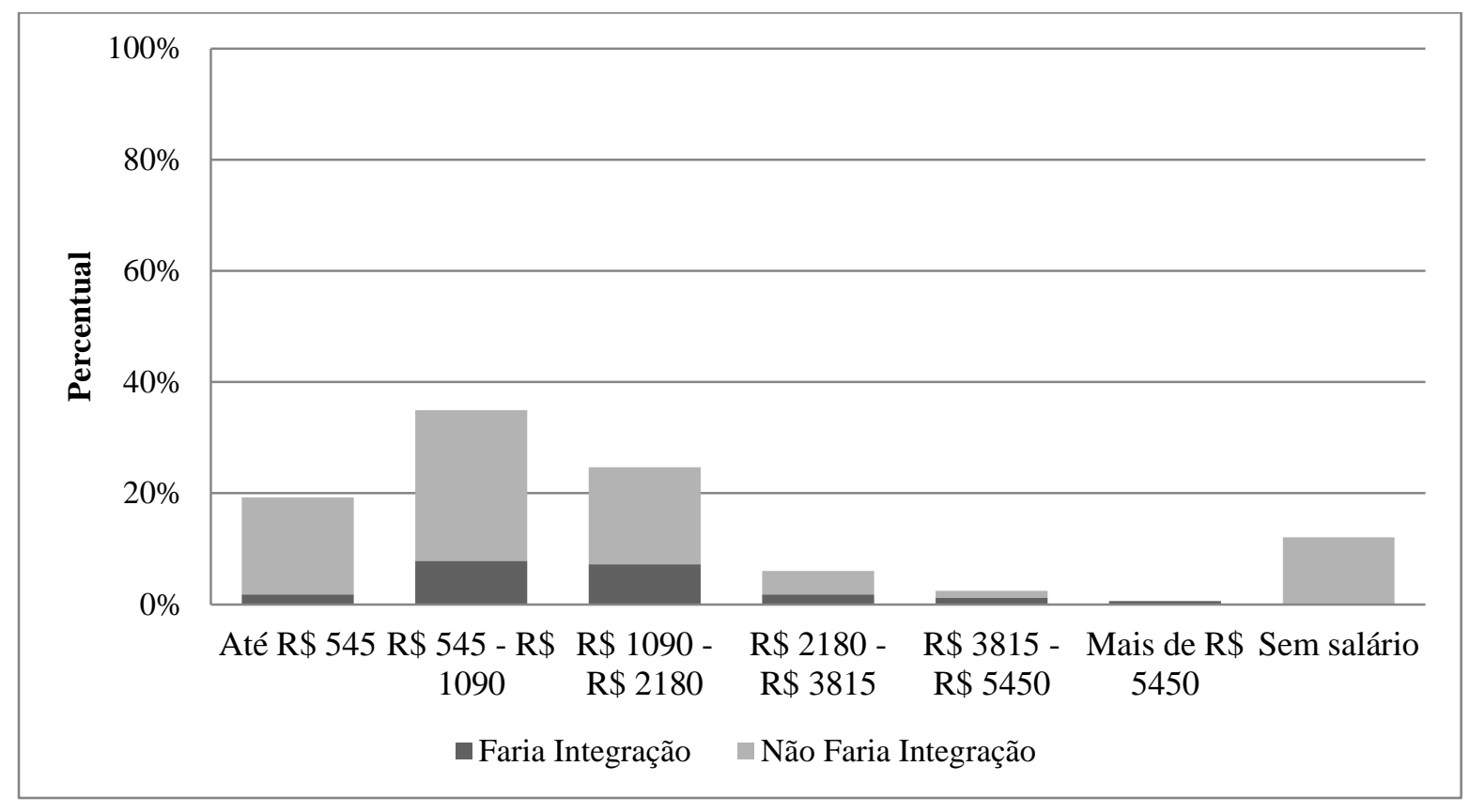

Figura 6 - Distribuição por intervalo de renda, da opção de fazer ou não integração ${ }^{6}$

Todos os entrevistados possuíam algum tipo de escolaridade, com destaque para os entrevistados que possuem ensino médio completo, dos quais $37 \%$ aceitariam realizar a integração (Figura 7).

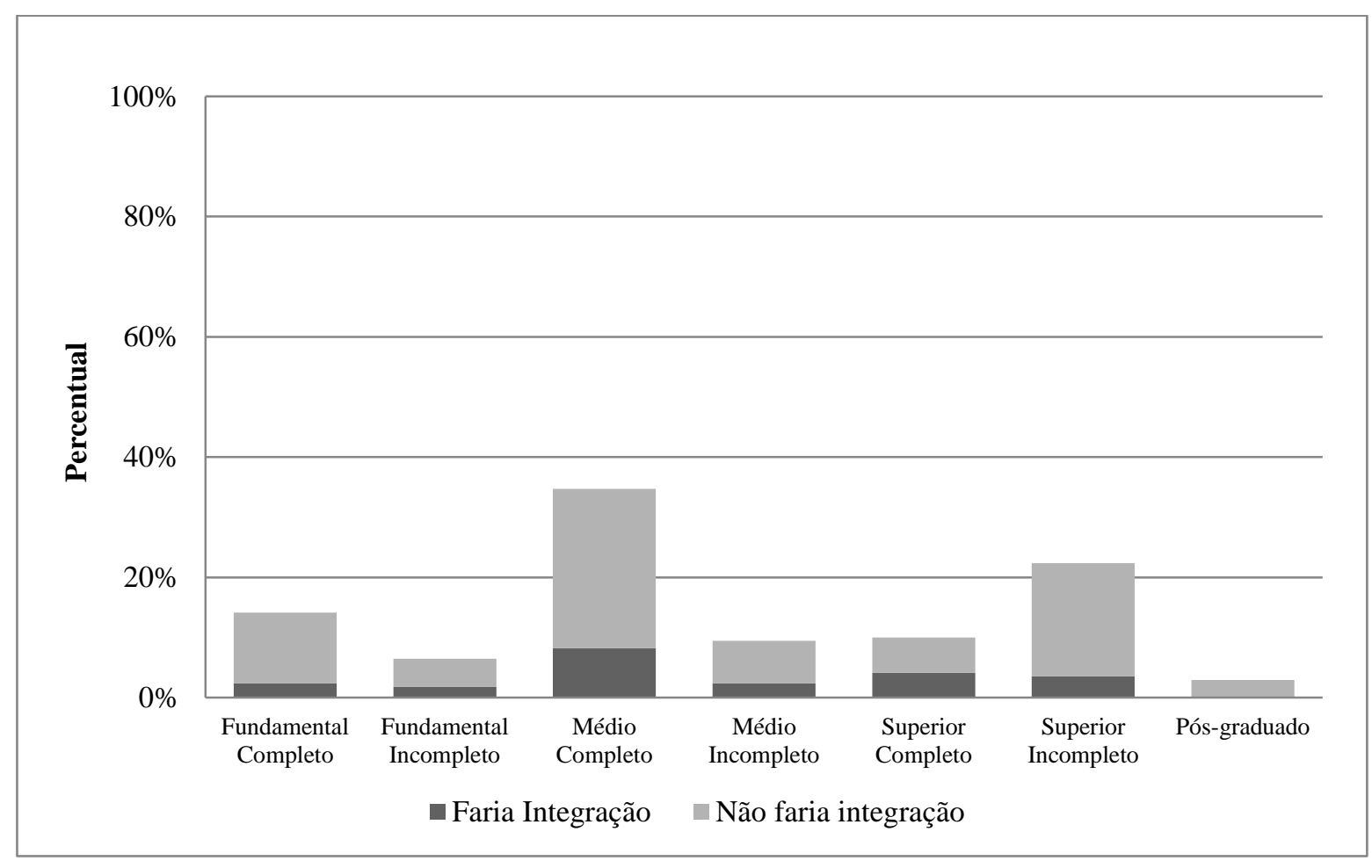

Figura 7 - Distribuição por escolaridade, da opção de fazer ou não integração ${ }^{7}$

\footnotetext{
${ }^{6}$ Fonte: elaboração própria.
} 
Relativamente à questão sobre um local adequado para deixar a bicicleta, pediu-se aos entrevistados para responder por ordem de prioridade em relação às seguintes opções:

- Dentro da estação;

- Com segurança;

- Coberto;

- Gratuito.

Para esta pergunta, em termos de resultados relevantes, foram apenas consideradas as respostas da população receptiva à integração. Dos resultados obtidos, destacou-se com $58 \%$ a opção "com segurança” como prioridade número 1, ou seja, a característica fundamental que um estacionamento adequado deve apresentar. A gratuidade do estacionamento aparece em segundo lugar com $26 \%$ de respostas.

Quando foi questionado o que impedia as pessoas de utilizar a bicicleta para se deslocar até à estação, a falta de segurança pública e de segurança viária foram os problemas mais citados nas respostas dadas pelos potenciais usuários do sistema de integração, amostra essa de 38 entrevistados (Figura 8).

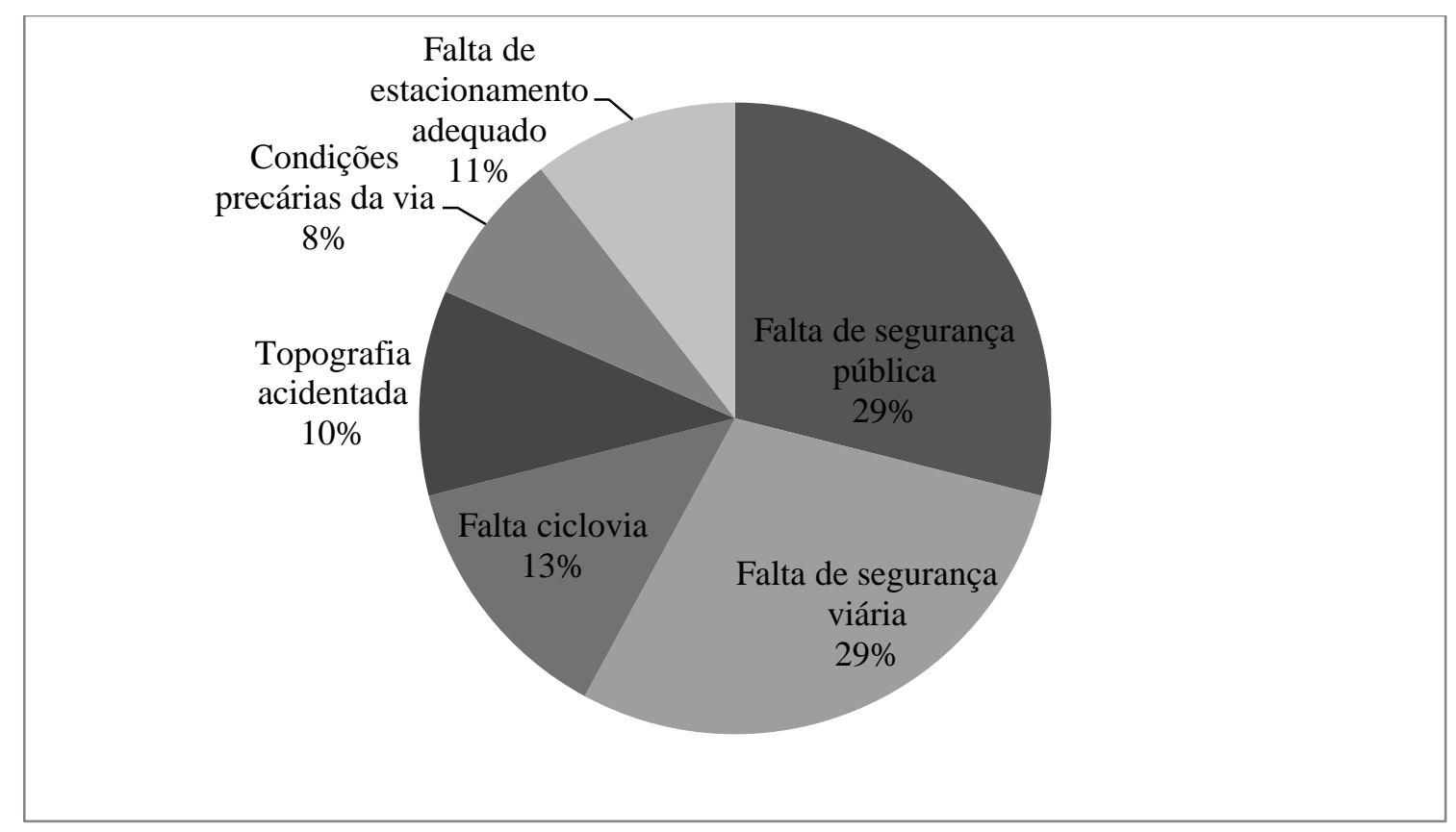

Figura 8 - Fatores que impedem a integração para os potenciais usuários ${ }^{8}$

\footnotetext{
${ }^{7}$ Fonte: elaboração própria.

${ }^{8}$ Idem.
} 
Dentre as 170 entrevistas realizadas 132 correspondem a pessoas que não estão dispostas a aderir ao sistema de integração. Ao serem questionados os motivos para a falta de interesse por parte das pessoas na opção de integrar a bicicleta com o transporte coletivo, nomeadamente o trem metropolitano, as razões mais relevantes foram a distância da origem até à estação (29\%) e o fato de grande parte não possuir bicicleta (30\%) conforme Figura 9. O sedentarismo aparece em terceiro lugar com 19\% de respostas. As intempéries climáticas apresentaram percentual inferior a $1 \%$.

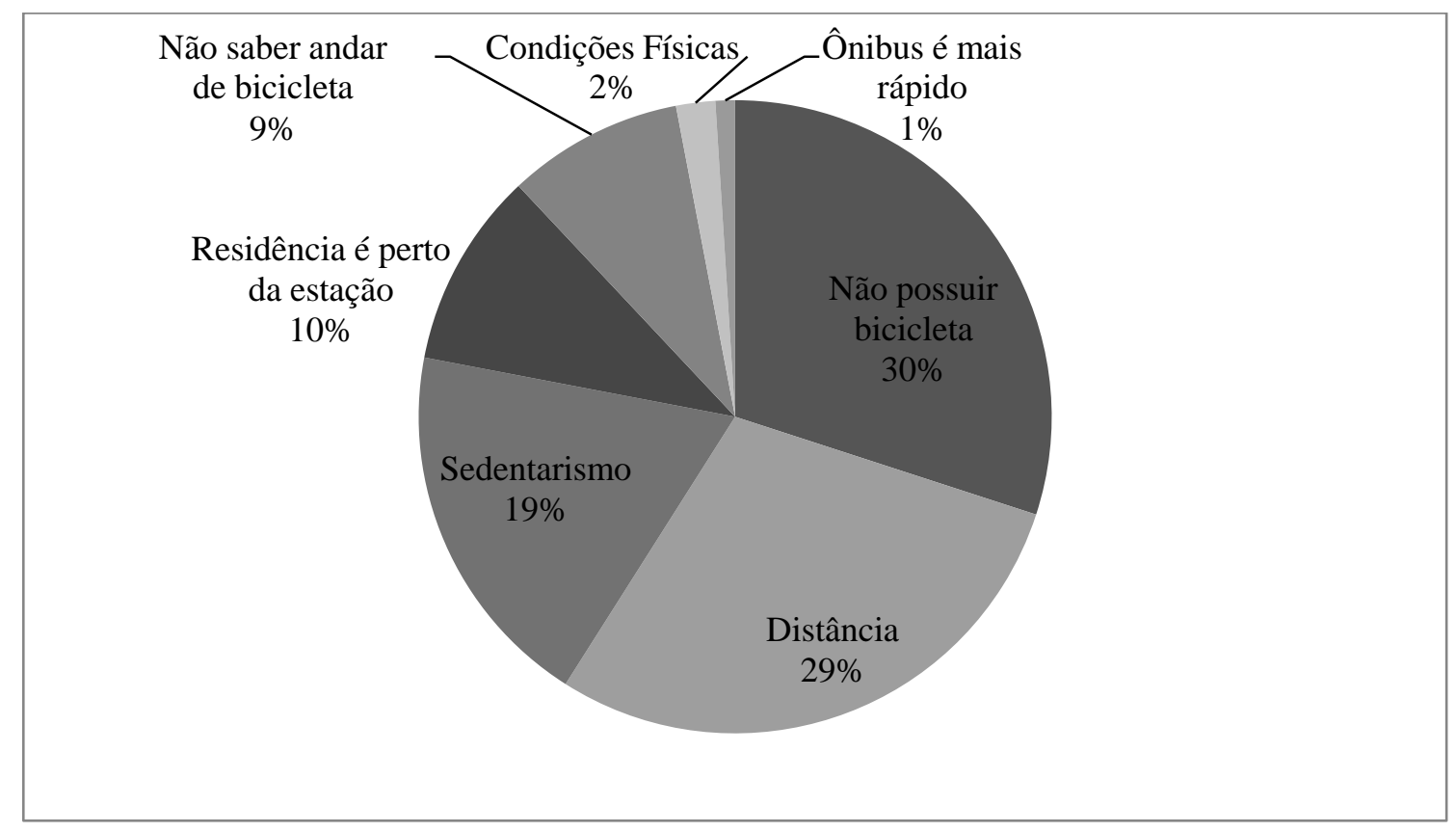

Figura 9 - Motivos da falta de interesse pela integração ${ }^{9}$

Resumindo, o perfil do potencial usuário é o seguinte: sexo feminino, idade entre 21 e 30 anos, desloca-se de ônibus para a estação, o motivo da viagem é trabalho/negócio, tempo de viagem de 10 a 20 minutos até a estação, possui renda entre $\mathrm{R} \$ 545,00$ e $\mathrm{R} \$ 1.090,00$, a ocupação predominante é funcionário de empresa privada e a sua escolaridade é ensino médio completo.

\footnotetext{
${ }^{9}$ Fonte: elaboração própria.
} 


\subsection{Pesquisa de preferência declarada}

A técnica de preferência declarada foi criada nos anos de 1970 por pesquisadores da área de marketing com a finalidade de avaliar comportamentos dos clientes. Ao longo dos anos, esta técnica tem sido desenvolvida noutras áreas, nomeadamente na área de transportes na qual é fundamental conhecer o comportamento das escolhas dos usuários. A aplicação das técnicas de preferência declarada tem como resultado, a indicação do cenário com maior potencial de ocorrer, dada uma determinada situação com uma dada combinação de atributos em cada cenário hipotético.

Para o estudo em questão foi utilizado um programa computacional desenvolvido para ajustes de modelos de preferência declarada, denominado Logit Multinomial com Probabilidade Condicional - LMPC (Souza, 1999). Através deste, os parâmetros são calibrados pela máxima verossimilhança, usando o método de ajuste de Newton-Raphson (Ben-Akiva e Lerman, 1985).

Para este experimento, foram considerados quatro atributos, sendo:

- Existência de ciclovia no trajeto até a estação (variável "ciclovia");

- Possibilidade de levar a bicicleta dentro do veículo de transporte público (variável "levar a bicicleta");

- Existência de bicicletário na estação (variável "bicicletário");

- Segurança pública durante o trajeto até a estação (variável "segurança”).

Para avaliar a taxa de adesão à integração da bicicleta com o transporte coletivo, dentre os 170 entrevistados, 100 se dispuseram a participar da pesquisa de preferência declarada, que teve por finalidade conhecer o comportamento dos entrevistados perante um conjunto de cenários de integração. Para cada um dos atributos, foram conferidos dois níveis, um correspondendo à situação de ocorrência do atributo e outro correspondendo à situação de inexistência do atributo. As informações foram apresentadas em forma de cartões aos entrevistados para que ordenassem em ordem de preferência os cenários apresentados.

De acordo com os resultados apresentados na Tabela 1, o panorama de respostas dadas pelos entrevistados foi coerente viabilizando a pesquisa realizada (Teste $t>1,96$ e valor de $0,2<$ Rho $<0,4)$. 
Tabela 1 - Resultados do LMPC ${ }^{10}$

\begin{tabular}{ccccc}
\hline Atributos & B & Erro & Teste t & IC (t=2,5\%) \\
\hline Ciclovia & 1,2231 & 0,0874 & 13,9945 & {$[1,048 ; 1,398]$} \\
Levar a Bicicleta & 0,6509 & 0,0791 & 8,2265 & {$[0,493 ; 0,809]$} \\
Bicicletário & 1,1221 & 0,0850 & 13,2063 & {$[0,952 ; 1,292]$} \\
Segurança & 1,3258 & 0,0884 & 15,0030 & {$[1,149 ; 1,503]$} \\
\hline
\end{tabular}

Outras estatísticas:

Rho $=0,3022 \quad$ Rho (Ajustado $)=0,2991$

$\mathrm{LR}=768,3354$

Os resultados reforçaram que a segurança pública durante o trajeto é fator preponderante para que os entrevistados utilizem a bicicleta na integração com o transporte coletivo, seguido pela existência de ciclovia e de bicicletário, como mostra a Figura 10. O intervalo de confiança das variáveis apresentadas na Figura 10 encontra-se na Tabela 1. Os resultados convergem para o trabalho de Silveira (2010), que reportou para o caso de Recife, que o maior empecilho para o interesse na integração bicicleta - metrô foi a falta de segurança pública.

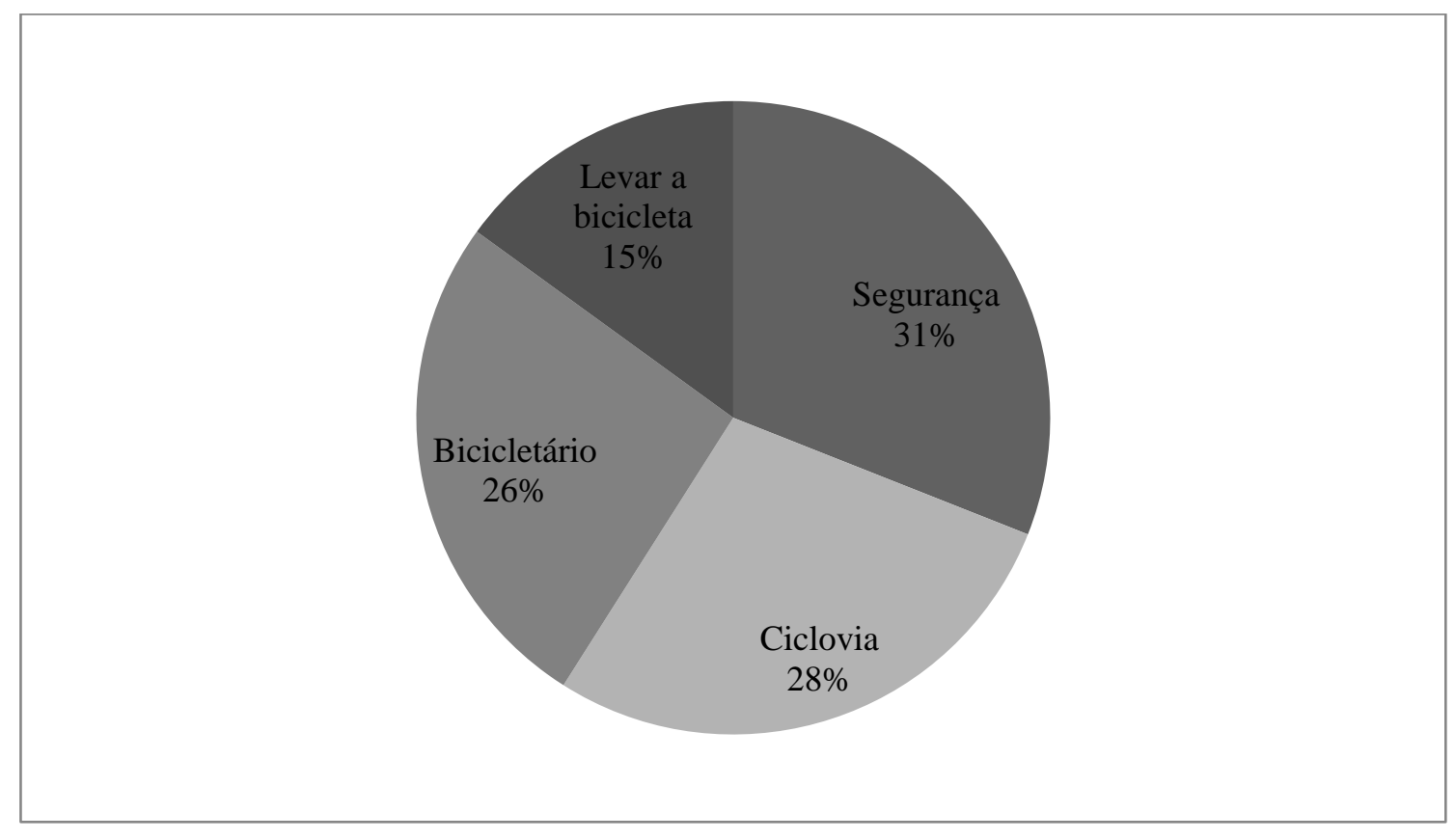

Figura 10 - Importância relativa de cada atributo na resposta dos usuários ${ }^{11}$

\footnotetext{
${ }^{10}$ Fonte: elaboração própria.

${ }^{11}$ Idem.
} 
Analisando a adesão dos entrevistados aos cenários apresentados, 30\% dos entrevistados fariam a integração para o cenário em que todos os atributos estivessem presentes (Tabela 2). Isto demonstra que a existência da segurança e da ciclovia são fatores preponderantes para a integração da bicicleta ao transporte coletivo.

Tabela 2 - Cenários com provável adesão dos entrevistados à integração da bicicleta ${ }^{12}$

\section{Cenário}

Existência da ciclovia, levar a bicicleta no metrô, existência de bicicletário e segurança pública.

Existência da ciclovia e de bicicletário e segurança pública.

Existência da ciclovia, levar a bicicleta no metrô e segurança pública.

\section{Percentual de Adesão}

$30 \%$

$16 \%$

$10 \%$

\section{Conclusão}

O presente trabalho teve por objetivo identificar os fatores que influenciam o uso da bicicleta e analisar como fomentar uma melhor qualidade de vida no meio urbano, tendo como principal destaque a mobilidade sustentável vinculada à integração da bicicleta ao meio de transporte público.

O estudo realizado na Estação Vilarinho em Belo Horizonte, Minas Gerais foi composto por duas pesquisas, uma socioeconômica com a finalidade de traçar o perfil do potencial usuário do sistema de integração da bicicleta com o trem metropolitano e outra de preferência declarada com o objetivo de avaliar o comportamento dos usuários da estação em face de uma série de cenários hipotéticos referentes ao tema da integração. Na primeira pesquisa concluiuse que a percentagem de pessoas dispostas a usar o sistema de integração é muito pequena relativamente àquelas que não pretendem utilizar a bicicleta como meio de transporte até a estação.

\footnotetext{
${ }^{12}$ Fonte: elaboração própria.
} 
O perfil do potencial usuário é: sexo feminino, idade entre 21 e 30 anos, desloca-se de ônibus para a estação, o motivo da viagem é trabalho/negócio, tempo de viagem de 10 a 20 minutos até a estação, possui renda entre $\mathrm{R} \$ 545,00$ e $\mathrm{R} \$ 1.090,00$, a ocupação predominante é funcionário de empresa privada e a sua escolaridade é ensino médio completo.

Os resultados encontrados refletem a população usuária da estação Vilarinho caracterizada por $65 \%$ do gênero feminino. Dos entrevistados que sabiam andar de bicicleta, $65 \%$ eram do sexo feminino, e a faixa etária mais expressiva foi de 21 a 30 anos. Providelo e Sanches (2010) verificaram diferenças significativas com relação à aceitabilidade ao ciclismo conforme: gênero (homens são mais favoráveis), idade (indivíduos mais velhos são mais favoráveis), tipo de ciclista (ciclistas que se consideram muito experientes são mais favoráveis), e frequência de uso da bicicleta (indivíduos que utilizam a bicicleta mais frequentemente são mais favoráveis). Todas as características mais favoráveis ao uso da bicicleta reportadas pelas autoras mencionadas não correspondem às características predominantes na amostra da estação Vilarinho. Este fato pode ser uma explicação para o baixo percentual de adeptos ao uso da bicicleta encontrado para esse estudo.

Relativamente à pesquisa de preferência declarada, concluiu-se que o atributo de maior relevância à integração da bicicleta com transporte coletivo é a segurança pública no sistema viário e o menos relevante é o transporte da bicicleta dentro do veículo de transporte público (trem). Como esta pesquisa baseia-se no campo das probabilidades, não se fez a distinção de quem efetivamente estaria disposto ou não a usar o sistema integrado. Os cenários resultantes das respostas dadas são hipotéticos e apenas permitem concluir que se tais cenários se verificassem, mesmo para os usuários não potenciais da integração, estariam reunidas as condições necessárias a uma boa integração intermodal, caso um dia o desejassem.

Relativamente à demanda existente para os paraciclos em operação na estação, há indicativo que o uso dos paraciclos não corresponde à população que normalmente utiliza o trem. Possivelmente diz respeito a usuários que deixam as suas bicicletas nos paraciclos e posteriormente se deslocam de ônibus, uma vez que na estação há integração com linhas de ônibus, ou por outro lado pode estar relacionado com as pessoas que trabalham na estação e que se deslocam de bicicleta. 
Reunindo a situação atual da Estação Vilarinho, onde já existe a integração entre ônibus e trem, com os resultados das pesquisas efetuadas, conclui-se que para a população usuária daquela estação o sistema de integração de bicicleta com transporte coletivo tem uma viabilidade reduzida, uma vez que a percentagem daqueles que não se interessam pelo sistema integrado é muito elevada. Essencialmente pelas respostas dadas pelos entrevistados concluise que a bicicleta ainda é um meio de transporte pouco atraente para a população usuária da Estação Vilarinho em Belo Horizonte.

Um contraponto interessante a esse resultado é o programa PedalaBH, iniciativa da Empresa de Transporte e Trânsito de Belo Horizonte - BHTRANS, iniciado em 2010, com o objetivo de promover e resgatar o uso da bicicleta na capital. A rede cicloviária planejada para a cidade será totalmente interligada com cerca de $380 \mathrm{~km}$ de ciclovias. No entanto, a cidade possui atualmente apenas $36 \mathrm{~km}$ de ciclovias, sem a continuidade e conectividade previstas. Desta forma, há indicativo que os incentivos e promoções feitos pelo órgão gestor ainda não atingiram a população da Região Norte, que não demonstrou interesse pela integração da bicicleta com o transporte público, conforme mencionado anteriormente.

A análise desenvolvida na Estação Vilarinho relativa à potencialidade da integração da bicicleta com o trem, é um dos estudos entre outros que ajuda a estimular os órgãos competentes a tomarem iniciativas referentes à implantação de infraestrutura adequada que facilite essa integração. Apesar dos resultados nessa estação terem sido pouco receptivos relativamente à integração, é necessário realizar mais investigações em vários pontos da cidade, pois a solução para a sustentabilidade urbana passa por um conjunto de ações e não apenas por uma solução isolada.

Além disso, uma importante contribuição do trabalho é a divergência em relação à adesão da integração da bicicleta ao transporte coletivo, conforme indica o resultado comparativo das pesquisas realizadas nas cidades de Belo Horizonte, Salvador, Recife e Rio de Janeiro, que aponta a necessidade de pesquisas locais mais detalhadas para avaliação do interesse pela integração. Divergências em relação ao uso da bicicleta também foram apontadas pelo estudo na cidade do Rio de Janeiro, em função da localização e da ocupação do entorno das estações pesquisadas. 
Desta forma, pode-se concluir que para promover a integração da bicicleta com o transporte público seriam necessárias políticas públicas de melhoria da segurança da população para encorajar o uso da bicicleta, associadas ao planejamento de transportes através da implantação de infraestrutura para a circulação segura de bicicletas, bem como melhorias operacionais nas estações que propiciem áreas seguras para estacionamento de bicicletas.

\section{Referências}

Associação Nacional dos Transportes Públicos - ANTP (1997) Transporte humano - cidades com qualidade de vida. São Paulo: ANTP.

Associação Nacional dos Transportes Públicos - ANTP (2008) Relatório geral 2008. Sistema de informações da mobilidade urbana. São Paulo: ANTP.

Ben-Akiva, M. e Lerman, S. (1985) Discrete choice analysis, Cambridge: MIT Press.

Braga, M. G. C. e Miranda, A. C. M. (2006) Análise dos sistemas cicloviários brasileiros e propostas para seu desenvolvimento. Congresso Luso-brasileiro para o Planejamento Urbano Regional Integrado Sustentável - PLURIS 2006, Portugal.

Gomide A. A. e Morato, R. (2011) Instrumentos de desestímulo ao uso do transporte individual motorizado: lições e recomendações. São Paulo: Instituto de Energia e Meio Ambiente.

IBGE (2010) Censo demográfico 2010. Instituto Brasileiro de Geografia e Estatística.

Martens, K. (2007) Promoting bike-and-ride: The Dutch experience. Transportation Research Part A, vol. 41 , pp. 326-338.

Ministério das Cidades (2006) Mobilidade e Desenvolvimento Urbano. Gestão Integrada da Mobilidade Urbana. Brasília: Secretaria Nacional de Transporte e da Mobilidade Urbana.

Ministério das Cidades (2007) Plano de Mobilidade por Bicicleta nas Cidades, Coleção Bicicleta Brasil, Caderno de referência para elaboração de Plano de Mobilidade por Bicicleta nas Cidades. Brasília: Secretaria Nacional de Transporte e da Mobilidade Urbana.

Monteiro, F. B. (2011) Avaliação de espaços urbanos para pedestres e ciclistas visando a integração com o transporte de massa. Dissertação (Mestrado) - Instituto Militar de Engenharia, Rio de Janeiro.

Pezzuto, C. P. e Sanches, S. P. (2004) Identificação dos fatores que influenciam o uso da bicicleta. XVIII Congresso da Associação Nacional de Pesquisa e Ensino em Transportes, Florianópolis.

Providelo, J. K. e Sanches, S. P. (2006) Proposta de um método para a definição de rotas cicláveis em áreas urbanas. XX Congresso da Associação Nacional de Pesquisa e Ensino em Transportes, Brasília.

Providelo, J. K. e Sanches, S. P. (2010) Percepções de indivíduos acerca do uso da bicicleta como modo de transporte. Transportes, v. XVIII, n. 2, pp. 53-61.

Ribeiro, D. M. S. e Freitas, I. M. D. P. (2005) A bicicleta como modo de transporte alternativo e integrado - o caso de Salvador, XIX ANPET Congresso da Associação Nacional de Pesquisa e Ensino em Transportes, Recife. 
Silveira, M. O. (2010) Mobilidade Sustentável: A bicicleta como um meio de transporte integrado. Dissertação de Mestrado em Engenharia de Transportes (COOPE), Universidade Federal do Rio de Janeiro.

Silveira, M. O., Balassiano, R. e Maia, M. L. (2011) A bicicleta como um modal de transporte integrado ao sistema de metrô da cidade de Recife. XXV Congresso da Associação Nacional de Pesquisa e Ensino em Transportes. Belo Horizonte.

Souza, O. A. (1999) Delineamento experimental em ensaios fatoriais utilizados em preferência declarada. Tese. (Doutorado em Engenharia de Produção), Universidade Federal de Santa Catarina. Florianópolis.

TCU (2010) Relatório e Parecer Prévio sobre as contas do Governo da República. Exercício 2010. Brasília: Tribunal de Contas da União.

Vieira, H., Valente, A. M., Pegas, H., Moreira, M. e Oliveira, A. M. (2010) O Planejamento Cicloviário: A busca da sustentabilidade a partir de erros e sucesso dos outros. $4^{o}$. Congresso Luso-brasileiro para o Planejamento Urbano Regional Integrado Sustentável - PLURIS 2010, Portugal. 